\title{
Ação monitória: primeiras impressões sobre a Lei 9.079, de 14.7.95*
}

\author{
Sergio Bermudes
}

Sumário: 1.Ressalva necessária; 2.Considerações propedêuticas; 3.Condições específicas; 4.Despacho Liminar; 5.Consolidação do título executivo; 6.Embargos.

1. Ressalva necessária. À confissão de precipitada aquiescência ao convite, sumamente honroso, para falar sobre a ação monitória, há menos de um mês da lei $\mathrm{n}^{\circ} 9.079$, de 14 de julho de 1995 , que a instituiu, seguiu-se o conselho de José Carlos Barbosa Moreira, mestre de todos nós, de que eu ressalvasse que a palestra revelaria as minhas primeiras impressões sobre $o$ instituto.

Aqui estou, então, para compartilhar com auditório tão qualificado as observações que, de pronto, suscita a lei $n^{\circ} 9.079$. Ela acrescentou, sob a rubrica "Da ação monitória", o capítulo XV ao título I do livro IV do Código de Processo Civil. Desdobrou-o em três artigos, identificados pelo número 1.102, acompanhado das letras $a, b$ e $c$. Evitou-se, assim, a renumeração de todos os demais artigos do Código, agindo-se sob a inspiração de modelos encontradiços na Europa e nos Estados Unidos. O Código de Processo Civil de Portugal, por exemplo, pospôs ao art. $65^{\circ}$ - que lá, como os demais, é ordinalmente numerado - o art. $65^{\circ}$-A; ao art. $228^{\circ}$, os arts. $228^{\circ}$-A e B; ao art. $234^{\circ}$, o art. $234^{\circ}$-A. Na Itália, a lei $\mathrm{n}^{\circ} 353$, de 26.11 .90 , juntou nada menos de treze artigos ao de $\mathrm{n}^{\circ} 669$ do Códice di Procedura Civile, apresentando o primeiro como 669-bis, e assim sucessivamente, até o décimo-quarto.

Não farei a resenha do quanto; do muito que já se escreveu na doutrina, especialmente da Europa, sobre o instituto objeto destas cogitações. Aqui estou para expor-lhes as minhas idéias, formadas, sem

* Discurso proferido na abertura da Semana do Advogado, simpósio realizado em homenagem ao Prof. Francisco Muniz entre 07 e 11 de agosto de 1995, pela Faculdade de Direito da UFPR, Ordem dos Advogados do Brasil - Seção do Paraná e Partido Democrático Universitário (Centro Acadêmico Hugo Simas).

R. Fac. Direito, Curitiba, a.28, n.28, 1994/95, p.43-54 
qualquer dúvida, sob o influxo do que eu possa ter lido e aprendido nos grandes autores, que se ocuparam do tema, como, por exemplo, e especialmente, Calamandrei, nos seus admiráveis estudos, reunidos no clássico livro Il Procedimento Monitorio nella Legislazione Italiana. ${ }^{1}$ Não posso abstrair o fato de que fui chamado a discorrer sobre uma lei, fortemente inspirada nos arts. 1.102-A a C do Anteprojeto de Modificaçã̃o do Código de Processo Civil da Comissão Revisora de 1985, que tive a honra de integrar, mas que se deve interpretar consoante a vontade dela própria e não conforme a minha. Pontes de Miranda censura os intérpretes, quando querem que a lei diga o que pensam, em vez de procurarem o conteúdo da regra jurídica. ${ }^{2}$ Tem razão.

Pela notória e benfazeja penetração do processo italiano no Brasil, antevejo esforços de se entender a nova lei mediante a importação, pura e simples, de normas do Codice di Procedura Civile, cujos arts. 633 a 656 regulam a figura, que agora aparece no nosso direito. Preciosíssimos embora os subsídios, que se podem recolher no que na Itália, na Alemanha e na Áustria se legislou, se escreveu ou decidiu sobre procedimento d'ingiunzione, Manverfahren e Mandatsverfahren, impõe-se a permanente lembrança de que os arts. 1.102, $a, b$ e $c$ compõem o Código de Processo Civil. inserindo-se nesse sistema, à luz de cujas normas se haverão de aplicar.

A ação monitória aparece no elenco dos procedimentos especiais. que se regem pelas regras que lhes são próprias, aplicando-se-lhes, subsidiariamente, as disposições gerais do procedimento ordinário, de acordo com o parágrafo único, acrescentado ao art. 272 pelo art. $1^{\circ}$ da lei $n^{\circ} 8.952$, de 13.12.94, mediante transposição do texto do anterior art. 273. Além das normas e princípios do procedimento ordinário, incidem, igualmente, regras do livro I do CPC, aplicáveis ao processo em geral e, particularmente, ao processo de conhecimento.

2. Considerações propedêuticas. Nulla executio sine titulo: eis o princípio fundamental do processo de execução, que encontra o seu pressuposto jurídico no título executivo, como explicitam normas insertas em

1 Calamandrei, as citações que farei, doravante, dessa obra referem-se ao vol. IX das Opere Giuridiche do autor, Morano, Napoli, 1983, onde também foi publicada.

2 Pontes de Miranda, Comentários ao CPC, tomo III, $2^{a}$ ed., Forense, Rio, 1979, p. 319. 
diversas leis (assim, v.g., os códigos português e italiano, respectivamente. nos arts. $45^{\circ}, 1$, e 474 , e o CPC brasileiro, no art. 583: "toda execução tem por base título executivo judicial ou extrajudicial").

Se existe título executivo judicial, que são os enumerados no art. 584. ou extrajudicial - os referidos no art. 585 - e se ocorreu o inadimplemento do devedor, que constitui o pressuposto fático da execução, conforme o art. 580 , o credor, ou o legitimado, que os arts. 566 e 567 identificam, pode promover a execução. Deve promovê-la para a satisfação do seu direito, não se admitindo que se valha do processo de conhecimento que, se iniciado, se frustraria com a sua extinção por sentença terminativa, pela falta de interesse processual.

Útil registrar, aqui e agora, que o art. $1^{\circ}$ da lei $\mathrm{n}^{\circ} 8.953$, de 13.12.94, aumentou o elenco dos títulos extrajudiciais, alterando o inciso I do art. 585. para nele incluir a debênture, e também o inciso II, para elevar à categoria de título suscetível de execução a escritura pública ou outro documento público, assinado somente pelo devedor; o documento particular assinado pelo devedor e por duas testemunhas, e o instrumento de transação referendado pelo Ministério Público, pela Defensoria Pública ou pelos advogados dos transatores, os quais - atendidos, claro está, os requisitos de liquidez, certeza e exigibilidade do art. 586 - se prestam de suporte jurídico à execução de qualquer crédito exeqüível, e não apenas do correspondente à obrigação de pagar quantia determinada ou de entregar coisa certa fungível, como constava da redação primitiva, onde só se aludia ao documento público e ao particular assinado pelo devedor e subscrito por duas testemunhas. Dessa expressiva ampliação, e também da possibilidade de converter-se em título judicial a transação, que não verse questão posta em juízo, a qual já constava, heterotopicamente, do art. 55 da lei do Juizado das Pequenas Causas e veio para o CPC pela reformulação do inciso III do art. 584 , através do $\operatorname{art.~} 1^{\circ}$ da citada lei ${ }^{\circ} 8.953$, decorrerá, necessariamente, o estreitamento do âmbito de incidência da ação monitória, que não pode ser usada, se couber a ação executiva.

Muitas vezes, não havendo título executivo, como o define a lei, indispensável para desencadear o processo de execução, no qual o Estado se alia ao credor, visando a satisfazer-lhe o direito, independentemente da vontade do devedor, ainda assim ocorrerá uma situação jurídica suficiente para gerar presunção de existência do crédito, dispensando a aprofundada e detida atividade de investigação que, habitualmente, se desenvolve no

R. Fac. Direito, Curitiba, a. 28, n.28, 1994/95, p.43-54 
processo de conhecimento, antes da declaração da existência do direito a uma prestação com a conseqüente condenação do devedor ao cumprimento dela. Imagine-se a carta, na qual um amigo agradece ao outro o empréstimo de dinheiro, enuncia o montante da soma e declara que irá pagá-la num determinado dia. Pense-se no bilhete, deixado pelo fazendeiro, na propriedade vizinha, onde afirma que apanhou certo número de sacas de café, que devolverá, impreterivelmente, em igual dia da semana seguinte. Sem dinheiro para pagar o transporte de livros, comprados na Espanha, em 1971, vi, numa fila no Aeroporto de Barrajas, a providencial figura de uma aluna. Obtive dela 150 dólares e dei-lhe um cartão de visita, agradecendo a gentileza e afirmando que lhe restituiria a importância, no Rio, até a tarde do dia seguinte. Ninguém deixará de descobrir, nesses exemplos, consistentes provas das obrigações, mas não se dirá que os documentos constituíram títulos executivos, pela manifesta falta dos requisitos, que a lei estabelece.

Numa opção política a axiológica, o direito permite que, em certas situações, se dispense o processo de conhecimento, na multiplicidade dos atos, que integram a sua estrutura tradicional, para a composição da lide oriunda da recalcitrância do devedor, resistente à pretensão do credor. A lei,.então, torna o processo cognitivo mais abreviado, mais ágil, mais útil, mais econômico, de sorte que, por meio dele, se possa concitar o devedor ao cumprimento da obrigação, cuja existência se presume, e, malograda essa iniciativa, constituir-se, sem delongas, o título necessário à execução.

Nesses casos, identifica-se o procedimento, que o processo cognitivo obedece, com o adjetivo monitório, sem dúvida, tanto quanto o verbo monir, um arcaísmo na linguagem comum, mas registrado nos léxicos, com o significado de aviso, admoestação, advertência, procedente de monere, advertir, lembrar, exortar, como ocorre nas litterae monitoriae do direito canônico, epístolas monitórias, através das quais a autoridade eclesiástica exorta alguém a se emendar, sob pena de excomunhão.

A lei n 9.079 - melhor, o Código de Processo Civil, com o enxerto dela decorrente - fala em ação monitória, tomando um dos efeitos decorrentes do seu ajuizamento. Se aludiu à ação de cunsignação em pagamento, à ação de depósito e à ação de usucapião, considerando o pedido do autor, consagrou o nomen iuris ação monitória, à vista de um dos aspectos marcantes do procedimento pelo qual se desenvolverá o processo formado pela propositura dela: a exortação devedor, de conteúdo moral também visível, no sentido de que cumpra a sua obrigação. 
Trata-se de uma ação de conhecimento, isto é, de uma ação que dá início a uma relação processual cognitiva, na qual a prestação jurisdicional de composição da lide não se faz de uma vez só. Verifica-se um daqueles casos, mencionados por Chiovenda, nos quais "la prestazione principale del giudice può adempierse in più volte" ${ }^{3}$ Depois de uma cognição sumária, o juiz defere a expedição do mandado de cumprimento da obrigação. Cumprido o mandado, só lhe resta declarar extinto o processo pela satisfação do direito do credor. Ocorrerá, aqui, embora não se trate de execução no sentido próprio, a hipótese do art. 794, I, do Código, na qual o devedor satisfaz a obrigação, cabendo ao juiz proferir sentença declaratória da extinção, semelhante à referida no art. 795. Descumprido o mandato, o processo se desenvolve, havendo nova prestação jurisdicional, variável no conteúdo, como se colhe na lei.

A cognição completa fica na dependência da oposição de embargos pelo réu. Calamandrei sustenta que, no processo da ação monitória, deixa-se ao devedor a iniciativa do contraditório. ${ }^{4}$ Entretanto, ele mesmo lembra a lição de Carnelutti, da qual diverge (p. 13, n.8) para quem o caráter fundamental do procedimento monitório consiste na eventualidade do contraditório. No meu fraco juízo, só cabe falar em inversão do contraditório, ou em eventualidade do contraditório, como notas dominantes, se se entender que constituem uma ação, não uma exceção, os embargos do art. 1.102, c. Tomados os embargos como resposta - e dessa questão tratarei daqui a pouco - será do autor a iniciativa do contraditório, que se efetivará do mesmo modo como se realiza no processo de conhecimento em geral. Ação ou exceção, os embargos asseguram o contraditório, respeitada, por isso, a garantia do art. $5^{\circ}, \mathrm{LV}$, da Constituição Federal, que, como de sabença correntia, não é preterida, quando a lei autoriza a outorga de providência inaudita altera parte, contanto que se possa exercer o direito de defesa.

Há muito se preconiza a adoção do processo monetário no Brasil, como fizeram, por exemplo, a Comissão Revisora do CPC, nomeada pelo Governo em 1985 (cf. o anteprojeto dela, publicado no suplemento do DOU de 24.12.85), e o eminente Professor Humberto Theodoro Júnior, que em

3 Chiovenda, Istituzioni..., vol. II, $2^{\text {a }}$ ed., Napoli, Jovene, 1936, p. 543.

4 Calamandrei, Il Procedimento... ,op. cit., p. 12 e 13.

R. Fac. Direito, Curitiba, a.28, n.28, 1994/95, p.43-54 
livro, datado de 1976, o apontava como meio de solucionar o problema da duplicata sem aceite. ${ }^{5}$

Velho e revelho é o instituto na Europa. Calamandrei, que o filia ao praeceptum executivum sine causae cognitione do direito comum. advoga, tenazmente, a sua origem italiana, chegando a dizer que a recepção do procedimento d'ingiunzione, no processo da Itália, não tem de imitação estrangeira mais do que teve o reingresso, nos museus do seu país, das obras de arte italianas, restituídas pela Áustria. ${ }^{6}$ Reconhece, contudo, que, para retomar a tradição, abeberou-se o legislador da Itália nas leis processuais alemãs. Se, na península, o instituto é introduzido, ou reintroduzido, a partir da segunda década deste século, ele já existia, na Alemanha e na Áustria desde a segunda metade do século XIX. Daí, a quantidade de estudos e julgados sobre a figura, que facilitarão a tarefa dos processualistas e profissionais do direito do Brasil.

Há um processo monitório puro, quando se admite a propositura da ação com base apenas na afirmação do direito do autor, desacompanhada de qualquer prova. Existe um processo monitório documental, quando se requer prova escrita da obrigação. A lei $\mathrm{n}^{\circ} 9.079$ adotou o processo monitório documental, como se lê no art. 1.102, a por ela acrescentado ao Código de Processo Civil: "a ação monitória compete a quem pretender. com base em prova escrita sem eficácia de título executiyo..."

3. Condições especificas. Exige-se, portanto, como condição específica da ação monitória - e, a partir daqui, passo a falar, exclusivamente, no direito positivo brasileiro - a existência de prova escrita da obrigação sem eficácia de título executivo. Cumpre também que a obrigação seja de pagamento de soma em dinheiro, ou, então, de entrega de coisa fungível, ou de determinado bem móvel, ainda que infungível, abrangidos no móvel os semoventes, como está no art. 47 do Código Civil. Excluíram-se, por mera opção valorativa do legislador, quaisquer outras obrigações.

5 Humberto Theodoro Júnior, O procedimento monitório como possivel solução para o problema da execução da duplicata sem aceite, Uberaba, ed. Vitória, 1976.

- Calamandrei, Il Procedimento... op. cit., p. 14. 
A situação jurídica, consubstanciada na prova escrita, referida no art. $1.102, a$, por certo não representa um título executivo. Pode-se, contudo, arriscar a afirmação de que ela, pela pretensão que fundamenta, configura um título paraexecutivo, pois dá origem a uma atividade jurisdicional semelhante à execução, a qual, partindo do pressuposto da existência do crédito, principia por uma ordem judicial de satisfação dele.

Corretamente, não se demorou o art. 1.102, a em tratar da eficácia da obrigação, regida por normas que o juiz aplicará na cognição sumária a que procede, conforme da sua função e como se extrai da primeira oração do art. $1.102, b$ ("estando a petição inicial devidamente instruída"), antes de deferir a expedição do mandado. Obviamente, o juiz ordenará a emenda da inicial insuficiente (art. 284), e a indeferirá, nos casos previstos no Código (art. 295), ou se verificar a nulidade da obrigação (v.g., examinando os documentos, descobriu que o devedor era absolutamente incapaz, quando assinou o escrito, ou que a obrigação é de entrega para abate de animais cuja comercialização a lei proíbe).

A petição inicial atenderá os requisitos do art. 282 do Código, cuja observância as normas da ação monitória não dispensaram. Não basta a afirmação do crédito, impondo-se que o autor ofereça ao juiz os dados necessários ao desempenho da jurisdição e ao réu, os elementos para a sua defesa, que só poderá vir por meio dos embargos.

A lei brasileira não foi minudente na disciplina da legitimidade ativa, ou passiva, para a ação moritória, como fez o art. 635 do CPC italiano, cuidando dos créditos do Estado e das entidades públicas. A legitimidade deve ser encontrada nas normas atinentes à relação jurídica documentada na prova escrita. Não vejo razões para não se admitir a ação monitória pelo Estado e pessoas da administração indireta, bem como por quaisquer pessoas físicas, jurídicas ou formais, nem contra todos esses entes.

4. Despacho liminar. Preceitua o art. 1.102, $b$ que "estando a petição inicial devidamente instruída, o juiz deferirá de plano a expedição do mandado de pagamento ou de entrega da coisa no prazo de quinze dias". O prazo de quinze dias é prazo processual, de cumprimento do mandado, não se podendo exigir o cumprimento em prazo menor, ainda quando este conste da prova escrita (v.g., "no dia tal, ou em cinco dias da interpelação extrajudicial ou judicial").

R. Fac. Direito, Curitiba, a.28, n.28, 1994/95, p.43-54 
Ao menos por enquanto, vejo o pronunciamento, que defere a expedição do mandado, como ato de prestação jurisdicional. Trata-se, no meu sentir, de sentença condenatória condicional, proferida na forma de despacho (ou de decisão interlocutória, para os que, como não penso, só admitem a existência de despachos de mero expediente). No seu primeiro estudo, sobre a estrutura do procedimento monitório, Calamandrei não hesita em afirmar: "acerca da natureza condicional da injunção me parece, pois, que não pode surgir dúvida alguma", logo após haver escrito que a injunção "tem, no momento em que emitida, a natureza de uma sentença contumacial suspensivamente condicionada". 7

A eficácia do mandado, ou melhor, do ato judicial que ordena a sua expedição fica suspensa até que (a) o devedor cumpra a obrigação, ou até que (b) se verifique sua contumácia, ou (c) se rejeitem os embargos por ele eventualmente opostos, proferindo-se, nos dois últimos casos, sentença complementar de declaração de eficácia da primeira, passando as duas, conjuntamente, a integrar o título judicial, que, então, se executará.

Não me parece que o réu da ação monitória possa recorrer do ato de deferimento da expedição do mandado. Faltar-lhe-ia interesse recursal, porquanto a lei põe ao seu dispor, no art. 1.102, c, embargos com efeito suspensivo da eficácia daquela ordem. O terceiro prejudicado, entretanto. sem legitimidade para embargar, poderá interpor recurso, que será o de agravo, desde que satisfaça o requisito do $\S 1^{\circ}$ do art. 499 . Dispõe o $\S 1^{\circ}$ do art. 1.102, $c$ que "cumprindo o réu o mandado, ficará isento de custas e honorários advocatícios". Essa norma resulta de uma clara opção política do legislador, que, aliviando o devedor dos ônus da sucumbência, o estimula ao cumprimento do mandado, do qual advém a célere composição da lide. Sem dúvida, a regra impõe sacrifícios ao autor, que, salvo nas exceções do art. 36, será, conforme essa norma, representado por advogado. que contrata e remunera, provendo, além disso, as despesas processuais, nos termos do art. 19.

Não se diga que o credor poderia evitar essa desvantagem, propondo ação de procedimento comum, em vez da moniéória. O princípio da infungibilidade procedimental - conforme o qual é a lei, não a parte, que determina

7 Calamandrei, Il Procedimento... op. cit., p. 42. 
qual o processo e como se haverá de desenvolver - o faria carecedor da ação, por falta de interesse, decorrente da inadequação da via eleita, se, na situação do art. 1.102, $a$, o demandante se servisse de remédio diferente do de que agora se trata.

5. Consolidação do título executivo. O mandado de pagamento ou de entrega da coisa, previsto no art. $1.102, b$, é a exteriorização formal do título executivo, situação jurídica decorrente da determinação judicial que ordena a expedição dele. Esse título, entretanto, é provisório, como ensina Calamandrei. ${ }^{8}$ Para tornar-se definitivo, constituindo pressuposto jurídico do processo de execução, será mister que não se oponham embargos (art. 1.102,c), ou que se rejeitem os embargos eventualmente opostos, conforme o $\S 3^{\circ}$ desse mesmo artigo.

No caso de rejeição dos embargos, há uma sentença, pois não se conceberia pudessem eles ser rejeitados, mesmo sem apreciação do pedido que por meio deles se deduziu, independentemente de um pronunciamento judicial.

Resta indagar se, igualmente, se faz necessário algum ato judicial, na hipótese de faltarem os embargos, ou de virem eles intempestivamente. Parece-me que sim, e por mais de um motivo. Diferente do processo de execução, com o qual não se confunde porque relação cognitiva, a extinção do processo da ação monitória, quando não houver embargos, dependerá de uma sentença, como acontece em qualquer outro processo. Seria temerário proceder-se à execução sem um ato judicial de reconhecimento da constituição do título - título executivo judicial, como está no art. 1.102, c, criado pela atividade jurisdicional do Estado - porque a ausência dos embargos não implica, necessariamente, a consolidação do título provisório, representado pelo mandado. Pense-se, por exemplo, na citação inexistente, ou nula. que acarreta a invalidade do processo, e impede a configuração da contumácia do réu.

Por conseguinte, urge que se profira uma sentença declaratória positiva de que se operou, de pleno direito, a constituição aludida no art. 1.102, c. Essa sentença completa a formação do título executivo judicial, consolidando-o, tanto quanto a sentença de rejeição dos embargos prevista no $\S 3^{\circ}$.

8 Calamandrei, Il Procedimento..., op. cit., p. 19.

R. Fac. Diresto, Curitiba, a.28, n.28, 1994/95, p.43-54 
Se deve haver sentença declaratória positiva, também poderá haver sentença terminativa de extinção do processo (v.g., verifica o juiz a ilegitimidade passiva ou ativa, descobre a falta de um pressuposto processual, como quando, morto o verdadeiro réu, citou-se um homônimo, que não cuidou de comparecer porque não dizia com ele a ação monitória).

Cabe, ainda, sentença declaratória negativa, que, tal qual a que acolhe os embargos, declara, na hipótese de falta deles, que não ocorreu a constituição do título executivo, se ausentes os pressupostos da respectiva formação. Viu o juiz, por exemplo, que a soma em dinheiro, reclamada na inicial, corresponde ao preço, estipulado pelo arbítrio exclusivo de uma das partes de uma compra e venda, nula, conforme o art. 1.125 do Código Civil, ou então verificou que o bem móvel reclamado, a cuja entrega o devedor se obrigara, foi por este recebido com inalienabilidade vitalícia. Plòsz, apoiado por Calamandrei ${ }^{9}$ afirma que, quando não há oposição do réu, o mandado monitório adquire eficácia executiva, não em decorrência de um acordo (no qual eu próprio cheguei a pensar, cogitando de um negócio jurídico processual, formado pela manifestação de vontade contida na omissão do demandado), mas pelo estabelecimento da certeza, por preclusão, dos atos afirmados pelo autor, os quais justificam a atuação da lei, no sentido da condenação do réu. Deve, então, o juiz indagar se, ocorrendo a preclusão, ela gerou o efeito de constituir o título, assim declarando, conforme o caso, na sentença afirmativa, ou negativa.

No tocante à ação monitória, não é a obrigação de pagamento ou de entrega que se executa. Executa-se o título executivo judicial, composto da ordem de expedição do mandado monitório, e complementado e consolidado pela sentença declaratória de constituição dele.

6. Embargos. Preceitua o art. 1.102, $c$ que, no prazo de quinze dias, assinado no art. 1.102, $b$ para cumprimento do mandado monitório, o réu poderá oferecer embargos, que suspendem a eficácia daquela ordem. Esses embargos se processam nos próprios autos da ação monitória pelo procedimento ordinário, não havendo lugar parà a prévia segurança da juízo, mediante penhora ou depósito, como tudo se extrai do $\S 2^{\circ}$ do mesmo art. 1102, c do Código de Processo Civil.

9 Calamandrei, Il Procedimento...,op. cit., p. 30 e ss. e n. 47. 
Depois de forte perplexidade, cheguei à conclusão - nada definitiva, como tudo quanto se pensa em matéria científica, em especial quando se examina lei recente - de que esses embargos têm a natureza de ação: ação constitutiva, pela qual se busca o desfazimento da eficácia da determinação, contida no mandado inicial.

Não me impressiona, suficientemente, o fato de haver o art. 1.102, $c$ falado em embargos, e o seu $\S 3^{\circ}$ na rejeição deles. Afinal, pouco significam os nomes de per si (resisto à tentação de repetir Shakespeare). No art. 755, concernente à insolvência requerida pelo credor, o Código chama embargos ao meio pelo qual o devedor impugna o pedido, sem os despojar, pelo batismo, da natureza de simples defesa; de exceção, que suponho terem. Também não basta, para a descoberta da natureza jurídica dos embargos, a regra do $\S 2^{\circ}$ do art. $1.102, c$, de acordo com a qual eles se processam nos próprios autos e não dependem de prévia segurança do juízo - pontos que até mesmo poderiam contribuir para afirmar que constituem resposta do réu - e se desenvolvem pelo procedimento ordinário porque haveria espaço para a interpretação de que, opostos os embargos, é o processo da ação monitória que segue o rito ordinário.

Quero crer que a natureza jurídica dos embargos decorre do fato de que eles se voltam, não diretamente contra o pedido do autor, mas contra 0 mandado monitório, cuja eficácia suspendem, e depois aniquilam, isto é, desconstituem, pela sentença de procedência, obstativa da formação do título, que tem na ordem inicial um dos elementos indispensáveis à sua formação. Nos embargos, invoca-se a jurisdição, buscando-se, não a improcedência do pedido da inicial, que já foi acolhido, embora condicionalmente, no pronunciamento que deferiu o mandado monitório. Postula-se a desconstituição desse pronunciamento. Dir-se-á, então, que o trânsito em julgado da sentença de mérito de procedência do pedido feito na ação de embargos não obstaria a que o autor formulasse o pedido de condenação de pagamento, ou de entrega, por meio de ação ordinária, ou sumaríssima. $\mathrm{O}$ ponto é delicado e apresenta-se digno da atenção dos grandes processualistas. Parece-me que, para se determinar a eficácia da coisa julgada da sentença de improcedência, se terá de verificar se ela alcançou apenas o mandado ( $v . g$., reconheceu a inexigibilidade do título porque ainda não chegara a termo o prazo de cumprimento da obrigação), ou se atingiu o direito do autor, negando-lhe a existência, como no caso em que declarou a nulidade da obrigação, atendendo a pedido formulado nos embargos.

R. Fac. Direito, Curitiba. a.28, n.28, 1994/95, p.43-54 
Porque ainda não se terá formado por inteiro o título executivo judicial, não se limitarão os embargos às matérias do art. 741 do Código de Processo Civil, admitindo-se que, por meio deles, se suscitem quaisquer defesas, tal como acontece na execução de título extrajudicial, onde incide o art. 745 .

Como é ordinário o procedimento dos embargos, ele seguirá as regras pertinentes do Código do Processo Civil, admitindo-se a citação do autor embargado por meio de intimação, tal como determina o art. 740. A natureza e a finalidade dos embargos mostram-se incompatíveis com a possibilidade de reconvenção, conquanto eles constituam relação processual cognitiva diferente do processo da ação monitória, sendo autor deles o réu do processo principal e vice-versa, invertendo-se, assim, as posições das partes da relação processual originária da qual os embargos acessório.

A eficácia suspensiva do mandado monitório, prevista no art. 1.102. $c$ depende do recebimento dos embargos, mediante o deferimento da respectiva inicial, como previsto no $\S 1^{\circ}$ do art. 739 , na redação do art. $1^{\circ}$ da lei $\mathrm{n}^{\circ} 8.953$ de 13.12.94, onde expressamente se alude ao recebimento deles.

No âmbito dos embargos de que agora se trata, como no processo monitório (ressalvada a irrecorribilidade do decreto inicial), o regime recursal é o do processo cognitivo, mas a apelação da sentença dos embargos não produz efeito suspensivo, diante do art. 520, V, com a redação do art. $1^{\circ}$ da lei $\mathrm{n}^{\circ} 8.950$, de 13.12.95.

Consolidado o título executivo judicial, no processo da ação monitória, ou dos respectivos embargos, a execução dele se faz mediante a instauração de relação processual executiva, tal como prevista nos capítulos II e IV do título II do livro II do Código. Opostos a ela os embargos do devedor do art. 741, caberá a alegação de coisa julgada, se versarem matéria já soberanamente decidida nos embargos opostos ao mandado monitório. 